\title{
Ships' energy efficiency management: organizational and economic aspect
}

\author{
Victoria Glavatskhih ${ }^{1 *}$, Alexander Lapkin ${ }^{2}$, Larisa Dmitrieva $^{1}$, Inna Khodikova ${ }^{1}$, and \\ Alexander Golovin ${ }^{1}$ \\ ${ }^{1}$ Odessa National Maritime University, Department of Logistic and Project Management, 65029 \\ Odessa, Ukraine \\ ${ }^{2}$ Odessa National Maritime University, Department of Management and Marketing, 65029 Odessa, \\ Ukraine
}

\begin{abstract}
Maritime transport plays an important role in economic development of society, because it carries about $85 \%$ of goods, but it consumes a significant amount of fuel resources, which has a serious impact on air pollution. Millions of tons of nitrogen oxides, sulfur oxides, soot, heavy metal compounds and water vapor are released into atmosphere each year. These factors influence constant search for more effective methods to reduce toxicity of exhaust gases and develop organizational and economic conditions for fuel usage.
\end{abstract}

\section{Introduction}

Despite the fact that maritime transport compares favourably with other types of transport in regards to profitability, it is also the first in regards to harmful gases emissions into atmosphere and environmental pollution. Marine vessels use heavy fuel, which contains a significant number of heavy and dangerous metals, and it has a significant impact on air and coastline pollution.

Annex VI (Rules for Air Pollution Prevention from Ships) to the International Convention for the Prevention of Pollution from Ships (MARPOL) 73/78 was implemented on 19 May 2005. Two sections are of the greatest importance for practice: Regulation 13, which establishes limits on nitrogen oxides (NO) emissions from marine diesel engines, and Regulation 14, which establishes limits on the sulfur content of marine fuels [1]. In October 2008, the 58th session of the International Maritime Organization (IMO) adopted a new version of Annex VI [2]. The new version of the rules establishes gradual (Tier I - Tier III) introduction of new standards with increasing requirements for them.

Harmful substances from ships that pollute marine environment include:

- fuel oil, lube oils and sludges;

- ballast water with certain chemical and biological content;

- toxic, anti-fouling coating.

Harmful substances that pollute atmosphere include:

- exhaust gases of ship power engines;

* Corresponding author: VGlavatskhih@gmail.com 
- emissions of ozone-depleting and other gases contained in ship mechanisms and devices [3].

At the beginning of 2015, amendments to the Convention came into force, which regulate sulfur amount in marine fuel used on ships whose routes pass in SECA areas (trading areas, which include the Baltic, North Seas and the English Channel, where ships must switch to low sulfur fuel). Mandatory requirements were adopted by the IMO Committee for the Protection of Marine Environment in 2016 by amending MARPOL Chapter 4 of Annex VI to the Regulations for the Prevention of Air Pollution from Ships [4].

According to the new Regulation 22A on collection and submission of data about actual consumption of marine fuel [5], vessels with a gross tonnage of 5,000 tons and more are required to collect data on the consumption of each type of fuel they use, as well as other additional data, including transport indicators. activities. These vessels account for approximately $85 \%$ of carbon emissions from international shipping.

From January 1, 2020, the requirements of the MARPOL Convention to prohibit the use of fuels with a sulfur content of more than $0.5 \%$ are extended throughout the whole international trading area [6].

\section{Results}

Fuel costs are the main cost item when using maritime transport. Therefore, it is important to develop a set of measures aimed at reducing fuel consumption in ships operation.

On the one hand, shipping time is one of the most important indicators of shipping company quality. But on the other hand, vessels operation at optimal speeds allows to achieve a significant reduction in fuel consumption and, as a consequence, a reduction in operating costs and emissions from ships. Therefore, when choosing the optimal vessels speed, it is important to maintain a balance between these two indicators.

River and especially sea vessels travel long distances with a set, usually constant speed, at which engines run in optimal mode for a long time, and therefore the exhaust gases contain a minimum of toxic substances.

Under normal conditions of operation, the main sources of pollution are ship power engines, as well as ballast water and water used for washing cargo tanks. First of all, ship power engines pollute atmosphere with exhaust gases, and then toxic substances partially or almost completely get into waters of rivers, seas and oceans accordingly, thus volumes polluting land and water environment are statistically connected. Using maritime transport data, it is possible to estimate amount of harmful emissions and damage to the environment. Maritime transport carries a large number of oil cargoes, which increases effect of water environment pollution due to significant hydrocarbons weathering. At the same time, tankers account for more than $50 \%$ of sea pollution with oil and oil products from maritime transport.

$\mathrm{CO}, \mathrm{CO} 2, \mathrm{CH}$ gases are heavier than air and are accumulated on the surface of water environment. $\mathrm{CO}$ and gaseous hydrocarbon emissions from vessels power engines are involved in oxidative reactions and eventually converted to $\mathrm{CO} 2$, which presence in atmosphere causes a greenhouse effect [7].

Considering that ship engines are the main consumers of high-sulfur heavy fuels - HighSulphur Fuel Oil (HSFO), to regulate emissions of SOx, in 2015 control area were introduced by IMO - Sulfur Emission Control Areas (SECA), which are shown in Fig. 1. 


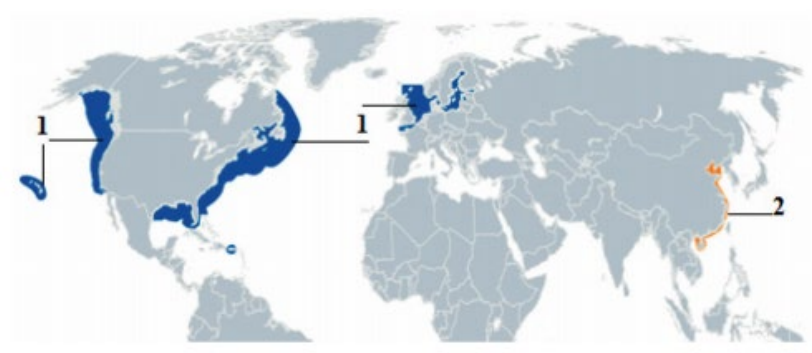

Fig. 1. SECA location and their limits: $1-0.1 \% ; 2-0.5 \%$.

The IMO, following allowability of using compatible low-oil fuel oil, has decided to globally limit the sulfur content of $0.5 \%$ for all trading areas, which came into force in 2020. This requirement is introduced in addition to the $0.1 \%$ sulfur limit in the North American and American areas of the Caribbean, North and Baltic Seas. In this case, vessels whose power engines are equipped with exhaust gas purification systems from sulfur content, will be allowed not to stop using HSFO (Table 1) [8].

Table 1. Regional and global sulfur regulators.

\begin{tabular}{|l|l|l|}
\hline \multicolumn{1}{|c|}{ Region } & \multicolumn{1}{|c|}{$\begin{array}{c}\text { Sulfur content limit } \\
\text { in fuel }\end{array}$} & Possibility to use scrubbers \\
\hline $\begin{array}{l}\text { All trading areas in } \\
\text { international waters }\end{array}$ & \multicolumn{1}{|c|}{$0,5 \%$} & \multicolumn{1}{c|}{ Yes } \\
\hline Control Areas (SECA) & \multicolumn{1}{|c|}{$0,1 \%$} & \multicolumn{1}{c|}{ Yes } \\
\hline The European Union & $0,1 \%$ in all port waters & $\begin{array}{l}\text { In some countries, the use } \\
\text { of open cycle is limited }\end{array}$ \\
\hline China & $\begin{array}{l}0,5 \% \text { B in national } \\
\text { waters in the 12-mile area }\end{array}$ & $\begin{array}{l}\text { No, only as an exception in } \\
\text { the case of a separate } \\
\text { application and additional } \\
\text { research }\end{array}$ \\
\hline California & $\begin{array}{l}0,1 \% \text { in the 24-mile } \\
\text { coastline area }\end{array}$ \\
\hline
\end{tabular}

Essential amendment to the regulation is "Carriage ban on HSFO in the Fuel System", with exception for vessels equipped with scrubbers. As earlier, it is allowed to carry HSFO as cargo, but it is forbidden to have HSFO in fuel system when scrubbers are not used. This amendment allows vessels using unsuitable fuel to be detained during Port State Control (PSC) without necessity to verify whether or not it has been used. It is expected that such amendments will significantly reduce possibility of violations of environmental legislation in international waters.

Expected increase in fuel costs, as many analysts of this sector predict, will lead to a certain slowdown in operating costs reduction. For the same reason, efforts will be focused on measures aimed at improving energy efficiency. Energy efficient vessels will be considered more competitive.

Vessels equipped with scrubbers can gain a significant competitive advantage. It is expected that vessels with scrubbers will initially be able to provide premium freight rates. However, if most vessels in a particular segment install scrubbers, the rates will be reduced as a result. Those vessels that will not be equipped with scrubber technology will be forced to reduce their rates to volatile levels and, ultimately, they may be pushed out of the market.

Therefore, it is very important for shipowners to monitor competition in their segment to ensure their dominance in the transport services market. 
Significant investments necessary for competitiveness in the context of global sulfur oxide limits, combined with the costs associated with ballast water treatment systems, may lead to the situation when older vessels will become unprofitable for further operation, which may be the reason for higher disposal activity and then fleet renewal using modern, more efficient vessels. This trend may also accelerate introduction of alternative fuels, such as LNG [9].

Switching to distillate or MGO (Marine Gas Oil) fuel will mean a significant increase in fuel and lube oil costs, and may require modernization of power engines in terms of fuel preparation due to significantly low fuel viscosity. Fuel tanks previously used for HSFO must be thoroughly cleaned prior to MGO bunkering to avoid contamination problems and, as a result, non-compliance.

The main problem with the use of MGOs or distillates is related to their availability and cost in the fuel market. Many analysts believe [10] that in the first few months after new requirements introduction, the price difference between HSFO and distillates will be very high, which will significantly increase fuel cost and make alternatives financially attractive.

It is expected that low sulfur fuel blends will be available in the market as a variety of products. However, desulfurization engines are very expensive, and their installation, implementation and commissioning can take several years before they start operating at full capacity [11]. Thus, most refineries prefer to process higher grade fuels rather than invest in desulfurization systems. It can be assumed that to meet the demand will make new fuel mixtures that will meet the desired limit of sulfur content less than $0.5 \%$, while reducing the cost by $10-15 \%$ compared to direct distillate fuels. The first fuel samples were presented at the end of 2018. It is likely that using new fuel mixtures will cause compatibility problems, and this will make fuel technological preparation a very important process for engine safe operation. Other problems associated with this type of fuel include long-term stability, impact on catalysts and relatively low flash point. Of great importance becomes quality control during bunkering, necessary to be confident that received fuel is in accordance with specification [12].

It is clear that using LNG as the main fuel will gain new benefits in context of new IMO limitations on sulfur emissions. LNG as marine fuel is technically proved solution, and bunkering infrastructure is developing rapidly around the world. Traditional fuel oils will remain the main fuel for most existing vessels in the near future, but commercial LNG opportunities are promising mainly for new ship designs, but in some cases also for conversion and modernization projects.

Thus, engine transferring to LNG should be carried out only on the basis of careful analysis of various information. In addition to commercial aspects, the main argument in favor of choosing LNG as a replacement for conventional fuel oils is a significant reduction in total air pollution from emissions of not only SOx but also NOx, as well as emissions of solids (Particulate Matter - PM).

Complete elimination of SOx and PM emissions - is potential to reduce NOx emissions by up to $85 \%$ - which contributes to using LNG, especially in control areas. In addition, LNG can reduce greenhouse gas emissions by $10-20 \%$ depending on engine technology. To sum up, using LNG has many benefits for both human health and the environment. addition, it also has a positive effect on ship's Energy Efficiency Design Index (EEDI). [13].

Initial data for calculating emissions of harmful substances and their dispersion into atmosphere are the annual consumption of fuel and materials consumed by emission sources, including merchant navy vessels [14].

The maximum emission of $i$-th substance $(g / s)$ from diesel engine is determined by formula:

$$
\mathrm{Mi}=(1 / 3600) \cdot \mathrm{eMi} \cdot \mathrm{Pe},
$$


where eMi - emission of i-th harmful substance per unit of useful diesel engine operation rated power mode, $\mathrm{g} / \mathrm{kWh}$; $\mathrm{Pe}$ - diesel engine operating power, whose value is taken from manufacturer's technical documentation, $\mathrm{kW}$.

Under unstable economic situation in the world, maritime industry is facing changing operating conditions. In order to remain competitive in the market, most shipping companies are forced to take measures to improve energy efficiency. This is partly due to changes in oil and fuel prices. Therefore, a lot of attention of shipping companies is focused on developing measures to reduce fuel costs. These include the following: measures to organize transportation (vessels redistribution; routes integration; operating speed reduction; service cessation in less profitable areas; improvement of navigation conditions), measures for technological improvement (improvement of hull design; new technologies for marine engines; using alternative energy sources; computer technology).

Next, let us consider one of the most effective measures to reduce fuel costs, which lies in vessel operating speed reduction. To do this, we will analyze dependence of fuel consumption on vessel speed. Isuues on dependence of fuel consumption on vessel speed and methods of choosing optimal operating speed was studied by many scientists, including [15-17].

Fuel savings during vessel operation might be achieved in several ways. One of them is to renew fleet with perfect vessels of new generation, which are equipped with modern economical engines. This way involves attracting significant investment. Another way to save fuel during vessel operation is to select and ensure optimal modes of marine engines operation, as well as to carry out various organizational and technical measures to save fuel and energy resources. Reducing speed during vessel operation allows the shipowner to reduce vessel operating costs, which is widely used in practice.

Based on known dependence of fuel consumption per day underway ( $q_{\text {underway }}$ ) on vessel speed (V):

$$
q_{\text {underway }}=\left(\frac{V}{V_{\max }}\right)^{a} *\left(q_{\max }-q_{\min }\right)+q_{\min }
$$

where ${ }^{a}$ - constant parameter ( $a=2,507849$ is set using the least squares method);

$V_{\text {max }}$ - maximum vessel speed, knots;

$q_{\text {max }}$ - fuel consumption at maximum speed, $\mathrm{t} /$ day;

$q_{\text {min }}$ - fuel consumption at minimum speed, $\mathrm{t} /$ day,

it is possible to determine the most appropriate vessels speed modes.

We have made calculations of fuel oil and diesel fuel consumption dependence by bulk carriers underway (type Handysize) with deadweight ranging from 32 thousand tons to 43 thousand tons.

As it can be seen from Figure 2 and Figure 3, at speed range up to 12 knots, the lowest fuel consumption refers to vessel " $D$ ", however, at range of more than 12 knots - priority is taken by vessel "A". And diesel fuel consumption varies in the range: from 12 knots for vessel "C" to 14.5 knots for vessel " $\mathrm{A}$ ". 


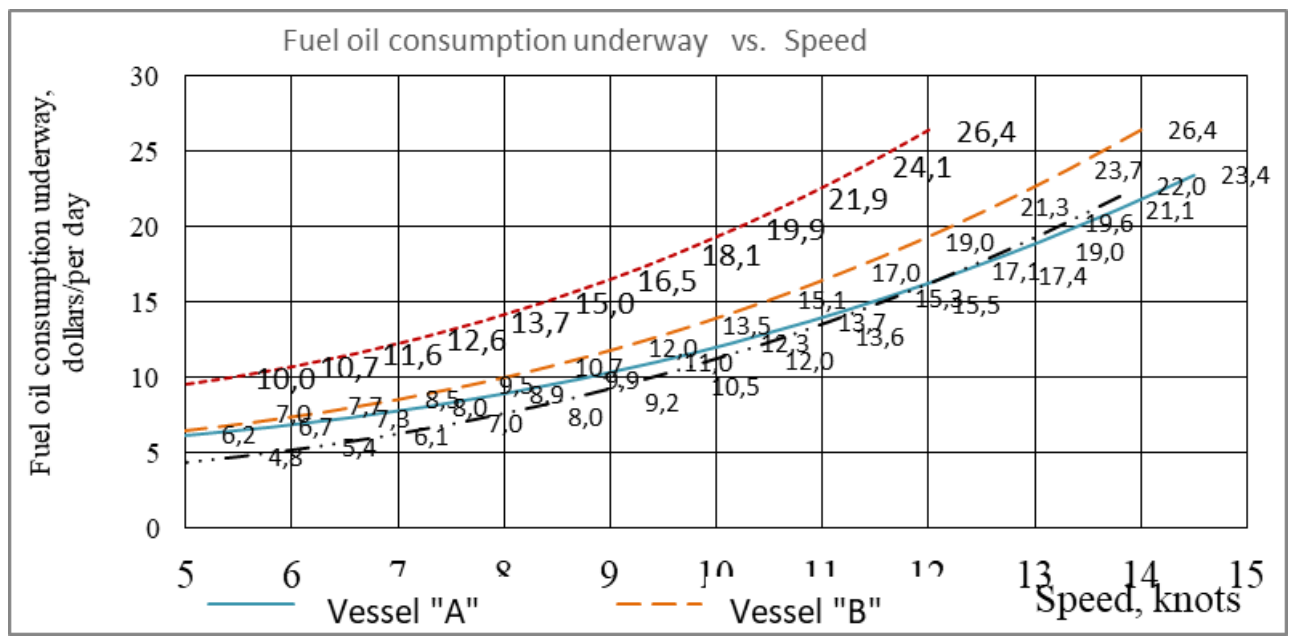

Fig. 2. Comparison of fuel oil consumption dependence on vessel speed for vessels under consideration.

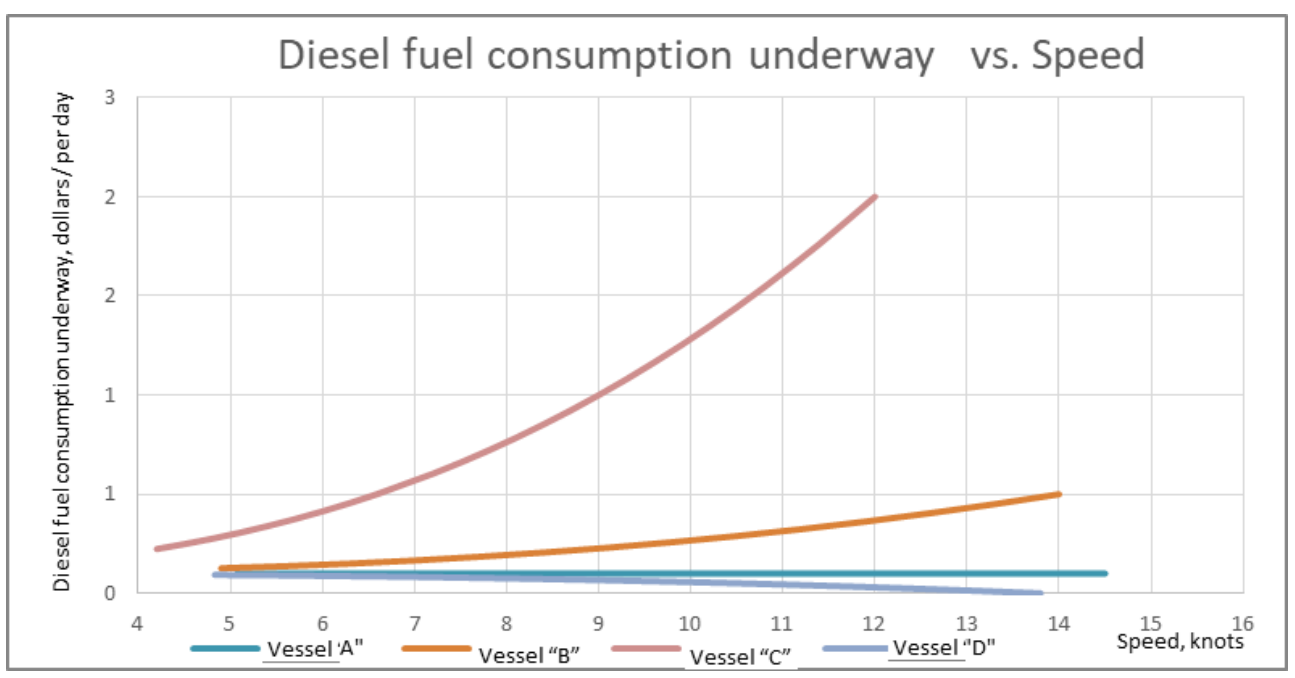

Fig. 3. Comparison of diesel fuel consumption dependence underway for vessels under consideration.

When choosing a vessel, you should also pay attention to the length of speed range at which vessel is optimally used. If vessel usage is optimal in a wide range of speeds, as in our case, for vessels "A", "C" and "D", shipping company in the future can provide additional flexibility in agreeing freight rates and shipping time through possibility of vessel efficient operation at different speeds, which also affects amount of harmful emissions into atmosphere and coastline areas [14].

\section{Conclusions}

It is important for maritime transport operation to reduce unit costs, the most important component of which is fuel costs and energy efficiency. Factors that determine rationalization process for their use can be divided into certain groups: 
1. Technological factors of resources efficiency include measures related to improving transport production. The same group of factors includes increasing level of mechanization and automation, rational consumption of fuel oil and lube oil, reducing norms of their usage on the basis of modern experience.

2. Constructive economy factors include group of measures aimed at improving design solutions and calculation methods. Especially important for marine transport is to increase operational reliability, reduce mass and dimensions of engineering factors.

3. Organizational and economic factors include measures aimed at improving organizational and economic conditions of using fuel. The basis of these measures lies in improving norm setting and efficiency of fuel and energy resources, improving conditions of their storage, utilization of thermal energy.

To sum up, the basis for fuel and energy efficiency in maritime transport is development and implementation of energy-saving and environmental technologies and improving fuel management.

\section{References}

1. Semanov, G.N. (2013). Harmful Air Emissions from Ships: Towards IMO Standards. $\mathrm{SPb}$.: Publishing house Science and transport. Sea and river transport.

2. MARPOL (2019). Revised MARPOL Annex VI. Rules for the Prevention of Air Pollution from Ships. http://rise.odessa.ua/texts/MARPOL_VI_19.php3

3. Bellona (2007). International Management Code for the Safe Operation of Ships and Pollution Prevention - ISM Code (Chapter IX SOLAS-74) ISM CODE. https://bellona.ru/2007/05/08/mezhdunarodnyj-kodeks-po-upravleniyu-b

4. MARPOL (2018). Guidelines for the application of the provisions of the International Convention MARPOL 73/78 (revised in 2018). https://files.stroyinf.ru/Index2/1/4293738/4293738163.htm

5. Verkhovna Rada of Ukraine (). About the consolidated Provisions about collecting the tributes, which are used in the form of the given tributes. https://zakon.rada.gov.ua/laws/show/835-2015-0D0\%BF\#Text

6. IMO (2020). Prospects for the shipping industry and refineries. https://modcon.ru/applications

7. European Environment Agency (2020). Atmospheric greenhouse gas concentrations. https://www.eea.europa.eu/data-and-maps/indicators/atmospheric-greenhouse-gasconcentrations-6/assessment

8. DNV GL (2021). Global Sulfur Cap 2020 - extended and updated. https://www.dnvgl.com/maritime/publications/global-sulfur-cap-2020.html

9. Petrov, A. P., \& Zhivljuk, G.E. (2019). Ecological safety of ship internal combustion engines. Selecting the efficient method for compliance with the new requirements of 2020 for sulfur emissions. Vestnik Gosudarstvennogo universiteta morskogo i rechnogo flota imeni admirala S.O. Makarova, 727-744.

10. Timofeev, O. Ya., Valdman, N.A., \& Kryzhevich, M.I. (2014). Features of the introduction of new requirements for the environmental safety of ships and offshore installations in the northern seas and on the Arctic shelf. Arctic: ecology and economics, 3 (15), 79-85.

11. Leontyev, A. I. (2018). Cleaning of diesel fuel. Desulfurization by the adsorption method. Business magazine Neftegaz.RU, 8, 62-70.

12. Petrov, A. P., \& Zhivljuk, G.E. (2019). Environmental safety. Limitation of sulfur emissions by the ship power plants. Vestnik Gosudarstvennogo universiteta morskogo $\mathrm{i}$ rechnogo flota imeni admirala S. O. Makarova, 130-145. 
13. Ivanchenko, A. A., Petrov, A. P., \& Zhivljuk, G.E. (2015). Energy efficiency of ships and regulation of greenhouse gas emissions. Bulletin of the State University of Marine and River Fleet named after Admiral S. O. Makarov, 3 (31), 103-112.

14. Lapkina, I.A., \& Glavatskikh, V.I. (2020). Management of the exploitation of vitrates of ships and the rules of MARPOL. II International Scientific and Practical Maritime Conference of the Department of SEU and TE of Odessa National Maritime University, MPP \& O-2020 (Marine Power Plants and Operation), 376-381.

15. Lapkina, I.O., Malaksiano, M.O., \& Glavatskykh, V.I. (2019). To the issue of the possibility of operating vessels at slow speeds Vernadsky, 30 (69), 134-140.

16. VG Marine Service (n.d.). Ecology of ship systems and crew. http://vgms.com.ua/esseecology-ship-systems-equip

17. Lapkina, I.A., \& Akimova, O.V. (2011). Determination of the optimal operating speed of container ships when changing the volume of traffic on the line. Method for managing the development of transport systems, 18, 165-181. 